\title{
Compressive strength of human openwedges: a selection method
}

\author{
H. Follet ${ }^{1, a}$, M. Gotteland ${ }^{3}$, R. Bardonnet ${ }^{2}$, A.M. Sfarghiu ${ }^{1}$, J. Peyrot ${ }^{4}$, and C. Rumelhart ${ }^{1}$ \\ 1 Laboratoire de Mécanique des Contacts et des Solides, INSA Lyon, Bât. Coulomb, 36 avenue des Arts, \\ 69621 Villeurbanne Cedex, France \\ 2 Laboratoire TBF, Bron, France \\ 3 Laboratoire de Vibrations et Acoustique, INSA Lyon, France \\ ${ }^{4}$ Clinique St Charles, Lyon, France
}

Received: 7 February 2003 / Received in final form: 2 October 2003 / Accepted: 14 October 2003 Published online (Inserted Later) - (c) EDP Sciences

\begin{abstract}
A series of 44 samples of bone wedges of human origin, intended for allograft openwedge osteotomy and obtained without particular precautions during hip arthroplasty were re-examined. After viral inactivity chemical treatment, lyophilisation and radio-sterilisation (intended to produce optimal health safety), the compressive strength, independent of age, sex and the height of the sample (or angle of cut), proved to be too widely dispersed [10-158 MPa] in the first study. We propose a method for selecting samples which takes into account their geometry (width, length, thicknesses, cortical surface area). Statistical methods (Principal Components Analysis PCA, Hierarchical Cluster Analysis, Multilinear regression) allowed final selection of 29 samples having a mean compressive strength $\sigma_{\max }=103 \mathrm{MPa} \pm 26$ and with variation [61-158 MPa]. These results are equivalent or greater than average materials currently used in openwedge osteotomy.
\end{abstract}

PACS. 87.19.Rr Mechanical properties of tissues and organs - 81.70.Bt Mechanical testing, impact tests, static and dynamic loads

\section{Nomenclature}

$h:$

$\beta$ :

$S_{1}, S_{2}$ :

$L:$

$a, b, d$ :

$F$ :

$E$ :

$a / F:$

$(b+d) / 2 E$ :

$E(a+b+d) / 3$ : characterises the mean surface area of

the cortex $\left(\mathrm{mm}^{2}\right)$

$S_{\text {tot }}$ : mean total surface area of cortical and spongy bone $\left(\mathrm{mm}^{2}\right)$

$S_{\text {cort }}$ : $\quad$ mean surface of cortical bone measured $\left(\mathrm{mm}^{2}\right)$

\footnotetext{
${ }^{a}$ e-mail: hefollet@iupui.edu
}

\begin{tabular}{|c|c|}
\hline$S_{\text {cort }^{*}}:$ & $\begin{array}{l}\text { ideal mean surface of cortical bone } \\
\text { (without porosity) }\left(\mathrm{mm}^{2}\right)\end{array}$ \\
\hline$S_{\text {cort calculated }}:$ & $\begin{array}{l}\text { surface area of cortical bone estimated } \\
\text { by calculation }\left(\mathrm{mm}^{2}\right)\end{array}$ \\
\hline Porosity: & $\begin{array}{l}\text { proportion of cavities in the apparent } \\
\text { part of the cortex of the bone }(\%)\end{array}$ \\
\hline$P_{\max }:$ & $\begin{array}{l}\text { maximal compression force recorded } \\
\text { during the test }(\mathrm{N})\end{array}$ \\
\hline$\sigma_{\max }:$ & $\begin{array}{l}\text { compressive strength, } \\
\sigma_{\max }=P_{\max } / S_{t o t}(\mathrm{MPa})\end{array}$ \\
\hline$\sigma_{\text {cort }}:$ & $\begin{array}{l}\text { maximal theoretical stress, ignoring } \\
\text { the strength of the spongy bone, } \\
\sigma_{\text {cort }}=P_{\text {max }} / S_{\text {cort }}(\mathrm{MPa})\end{array}$ \\
\hline$\gamma:$ & slenderness ratio $(-)$ \\
\hline$\rho:$ & radius of gyration $(\mathrm{m})$ \\
\hline Inertia ${ }_{\text {cortical }}$ : & $\begin{array}{l}\text { second moment of the area of mean } \\
\text { cross section of the cortical bone }\left(\mathrm{mm}^{4}\right)\end{array}$ \\
\hline$S_{W}:$ & $\begin{array}{l}\text { minimum cross section of the whole } \\
\text { cortical bone }\left(\mathrm{mm}^{2}\right)\end{array}$ \\
\hline$\tau_{\text {ultimate }}:$ & ultimate shearing stress (MPa) \\
\hline$\sigma_{\text {ultimate }}:$ & $\begin{array}{l}\text { ultimate stress under compression } \\
(\mathrm{MPa})\end{array}$ \\
\hline$\alpha:$ & coefficient of friction Bone/Steel \\
\hline$\tau_{\beta}:$ & shear stress connected to $\beta$ (MPa) \\
\hline$\alpha_{\alpha}:$ & shear stress connected to $\alpha(\mathrm{MPa})$ \\
\hline
\end{tabular}




\section{Introduction}

In order to correct mechanical or bone axes in orthopedic surgery an osteotomy is frequently undertaken. The aim of this osteotomy is to treat certain medial femoro-tibial arthroses (wear affecting the medial part of the articulation in genu varum). To do this, it is possible to remove a bone wedge (closing wedge osteotomy) or to add a wedge (openwedge tibial osteotomy), most frequently by using an autologous bone graft taken from the pelvis or with a biomaterial of natural (bovine bone) or synthetic (hydroxyapatite, bioceramic...) origin.

The surgical procedure, via a short essentially anteriomedial approach, consists of cutting an osteotomy line with the saw guided by a pin previously implanted using an image intensifier. The trace starts from the medial aspect of the tibia and becomes flush with the superior part of the fibula leaving an external hinge. The superior metaphyseal osteotomy passes at the level of the anterior tibial tuberosity and has a plane inclined backwards following the tibial slope. Opening consists of applying pressure to make the gap widen until the required separation is obtained. The correction is maintained by inserting a wedge into the opening, the height of this wedge having been determined before the operation, during the planning stage, as a function of the correction desired and the width of the tibia. Valgisation must not exceed $12^{\circ}$ taking into account the risk of lowering the patella. The assembly is generally consolidated by osteosynthesis. Depending on the discomfort caused, this will be removed 12 to 18 months after the operation $[1,2]$.

Biphasic synthetic products (HAP and TCP) as well as bovine trabecular xenografts have a mechanical strength in the region of $10 \mathrm{MPa}$ [3-5] which is too low to envisage their use for osteotomy. Biomaterials such as the exoskeleton of polyps (marine invertebrates) or synthetic bioceramics of the hydroxyapatite type provide on the other hand strengths in the range of $[25-100] \mathrm{MPa}$ perfectly appropriate for the stresses involved $[6,7]$.

With a view to using osteotomy wedges of compact bone obtained from the neck of the human femur, we showed in a previous study [8] that, without special precautions, the compressive strength of such substitutes ranged from 10 to $158 \mathrm{MPa}$ and that the height, the angle of the wedge and the sex of the donor had no significant influence on this. In order to reduce the wide range of strength provided, we have studied the influence of the geometry and the apparent porosity of the sample in order to determine simple objective criteria for the selection of grafts, using statistical methods (principal components analysis PCA, hierarchical cluster analysis, multilinear regression).

\section{Materials and methods}

The series of 44 samples ( 27 women, 17 men, $70 \pm 12$ years old, [43 to 94 years old]) previously studied [8], was selected without particular dimensional criteria, apart from the height and angle of cut of the wedges (Fig. 1).

\subsection{Origin and preparation of the bone wedges}

\subsubsection{Origin of the bone wedges}

The bone wedges were prepared from the neck of the femoral head. Recovery of them and safety measures were carried out by a tissue bank. The heads of the femurs came from patients who had undergone operations for hip arthroplasty and were selected according to clinical and biological criteria which meet strict health safety regulations. The bone tissue was then cleaned, decontaminated and sterilised using a process which combines mechanical and chemical treatment, lyophilisation and radiosterilisation.

This process aims to preserve the healthy bone structure, excluding the medulla, the cartilage and the insertion of ligaments, as opposed to cryo-conservation [9]. It follows from this that there is an improvement in osteoconduction, the possibility of storage at ambient temperature and presentation in forms suitable for various sizes of defect.

\subsubsection{Preparation of the samples}

The 44 samples had been taken from the base of the necks of the femoral head from 27 women and 17 men $(70 \pm$ 12 years old, [43 to 94 years old]) (Fig. 1a). The wedges were sawn using a band-saw (Perfekta Plus MKB 649, $v=17 \mathrm{~m} . \mathrm{s}^{-1}$, blade $\left.1750 \times 15 \times 0.45 \mathrm{~mm}\right)$ with an angle of cut $\beta\left(6,8,10\right.$ and $\left.12^{\circ} \pm 0.5^{\circ}\right)$ and a maximum height $h$ corresponding to the angle of cut $(6,8,10$ and $12 \pm 0.5 \mathrm{~mm}$ respectively).

For the mechanical tests, the wedges were sectioned (experimental cutting plane) at $L=1 \mathrm{~cm}$ from the periosteal border of $S_{2}$ with a diamond saw (BUEHLER®) ISOMET saw, Low speed) without fluid, in order to keep only the "useful part" of the sample (Figs. 1b, c).

\subsection{Preliminary measurements}

The two faces of each sample $\left(S_{1}\right.$ and $\left.S_{2}\right)$ were digitalised with a scanner (EPSON GT-6000 scanner, resolution $600 \mathrm{dpi}, 255$ grey levels) before the test, in order to measure the different geometric and surface area parameters. Each face was then binarised and only the bony parts (cortical and spongy bone) were measured.

\subsubsection{Measurement of the surface areas}

The surface area chosen was the mean of the surface areas $\left(S_{1}\right.$ and $\left.S_{2}\right)$ measured on faces 1 and 2 . In fact, depending on the cutting plane of the osteotomy wedge in the femoral neck (more or less proximal, Fig. 1a), the difference in thickness of the cortex between face 1 and 2 can be important, with a mean difference of $20 \%$.

The digitalised views of faces 1 and 2 of a wedge are shown in Figures 2a, b. 


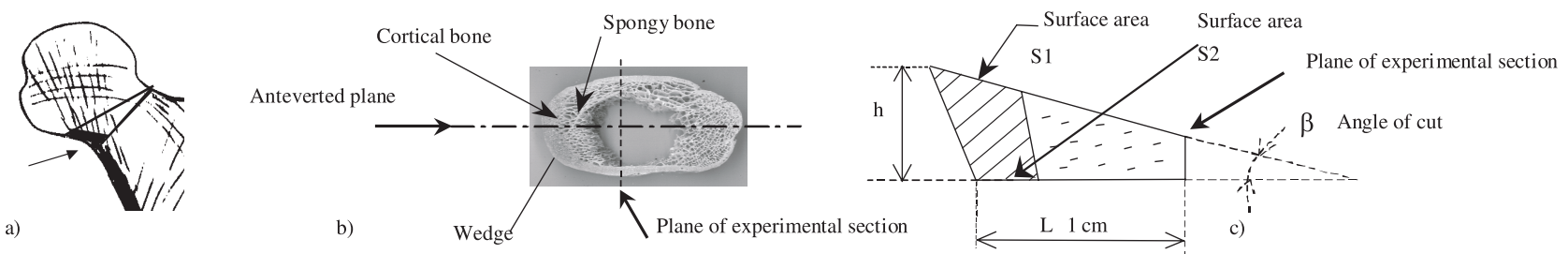

d)

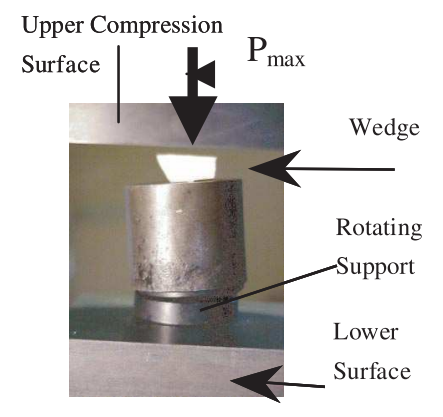

Fig. 1. (a) Obtaining a wedge; (b) wedge viewed from above; (c) diagram of a wedge, viewed in section; (d) compressive test.

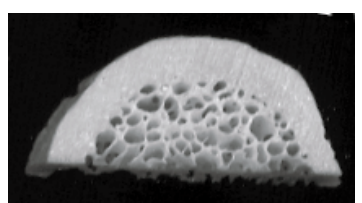

a)

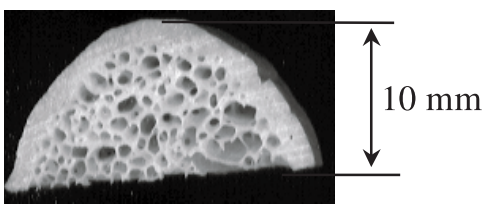

b)

Fig. 2. (a) Face 1; (b) face 2.

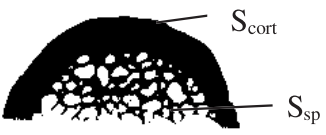

a)
$S_{\text {cort }}$

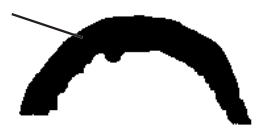

b)
Fig. 3. (a) $S_{\text {tot }}=S_{\text {cort }}+S_{s p}$; (b) $S_{\text {cort }}$.

A threshold, adapted for each sample, was choosen (between 0 and 255) to binarise the surface areas.

A program developed in Visual Basic allowed determination of the total surface area (porosity deducted), by counting the number of pixels on a given view, depending on the resolution chosen $(600 \mathrm{dpi}$, i.e. $\approx 40 \mu \mathrm{m})$.

Separation of the cortical $\left(S_{\text {cort }}\right)$ and spongy $\left(S_{s p}\right)$ surface areas was made visually by smoothing out the endosteal membrane and using the curve of the periosteal membrane as a basis for this (Fig. 3). The measurement of the cortical surface area $S_{\text {cort }}$ and the total surface area $S_{\text {tot }}$ takes into account the fact that porosity holes or osteophytes may be present.

Example on face 1 of the representation of the total surface area $S_{\text {tot }}$ and the cortical surface area $S_{\text {cort }}$ (Figs. 3a, b).

\subsubsection{Measurement of apparent porosity}

This measurement partly quantifies the quality of the cortical bone when the latter shows apparent porosity. The porosity of the spongy bone is taken into account in the measurement of the total surface area

$$
\text { Cortical porosity }(\%)=\frac{S_{c o r t^{*}}-S_{c o r t}}{S_{c o r t^{*}}} \times 100
$$

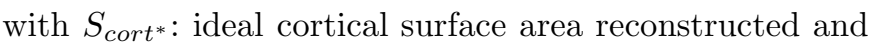
calculated from a scanned image by filling in the porosity holes.

This operation was carried out on the 2 faces and the results given correspond to the mean apparent porosity between faces 1 and 2. Figure 4 gives the results obtained on face 1 of a bone wedge (woman, 65 years old, apparent cortical porosity $4.4 \%$ ).

\subsubsection{Measurement of the geometric parameters}

From the digitalisation of the surfaces $S_{1}$ and $S_{2}$ and knowing the resolution of the images, the different values for thickness and width can be obtained by measuring these dimensions directly on the screen. Each of these measurements is the mean of measurements made on faces 1 and 2 (Fig. 5). 


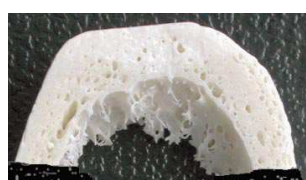

a)

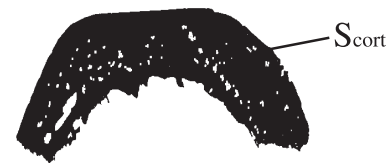

b)

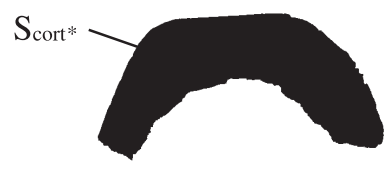

c)

Fig. 4. (a) Initial image face 1 cortical + spongy; (b) $S_{\text {cort }}$; (c) $S_{\text {cort* }}$.

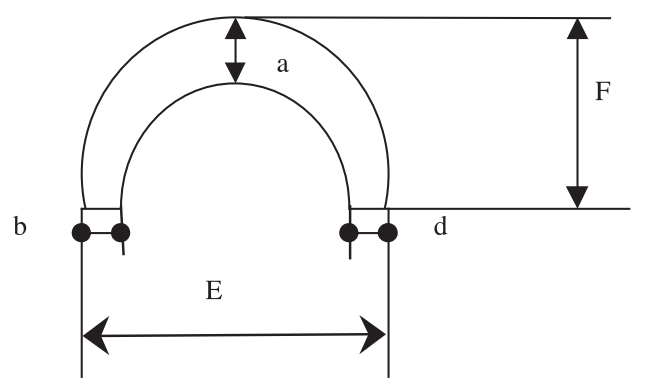

With:

a, b, d : Mean cortical thicknesses,

F : Mean length of the wedge,

E : Mean width of the wedge.

Fig. 5. Representation of the geometric parameters.

\subsection{Compression tests}

Compression tests were carried out at ambient temperature $\left(20^{\circ} \mathrm{C}\right.$, on "dry" sample) on a computer controlled Schenck RSA 250 traction-compressive machine. Each osteotomy wedge was placed on a pivoting support. The compression force $(P)$ was progressively applied to the wedge with a speed of movement of $0.5 \mathrm{~mm} / \mathrm{min}$ to obtain a quasi-static displacement (Fig. 1d).

Using the maximum recorded force $\left(P_{\max }\right)$, corresponding to the rupture, it is possible to calculate a limit stress $\sigma_{\max }=P_{\max } / S_{t o t}$ characterising the compressive strength of the wedge, while ignoring the shearing effect inherent in frictional forces and to the angle $\beta[6]$.

\subsection{Statistics}

The samples tested form part of a non-paired series (one bone wedge per individual). Statistical analyses were carried out using the Unistat $囚 5.0$ program for Windows and Matlab. For the descriptive statistics, the results are presented as follows: the mean, the standard deviation and the variation range indicating the minimum and maximum values of the data.

In order to separate the variables essential for our analysis, we used principal components analysis (PCA) [10]. PCA deals with tables crossing $N$ individuals in the statistical sense of the term with $K$ quantitative variables (here the individuals were represented by the bone wedges tested and the quantitative variables were the thicknesses, the surface areas, the porosity, etc.). PCA allows the dimensions of the space necessary to preserve a "good picture" of the cloud to be reduced, by searching for new orthogonal axes called principal axes. Two types of graph are obtained: graphs where each individual is interpreted as a point in a space of dimension $K$ and graphs where the variables which are most correlated with the principal axes and most correlated between themselves are indicated. The latter interpretation is used above all.

As stress depends on a reference surface area, a classic multilinear regression (stepwise regression) was used [11] with the aim of obtaining an analytical formula for determining the cortical surface area.

Finally, to form a representative group providing a mean strength at optimal compression, hierarchical cluster analysis (HCA) was undertaken. Starting from a table of individuals, the latter is based on the calculation of Euclidean distances between each pair of points taken among the $N$ samples, with the coordinates introduced by the selected variables (geometric, porosity, etc.). Division of the population into disjointed groups is sought optimising a criterion which tends to:

- only group two individuals together if they are very similar;

- only separate individuals who are sufficiently different.

Then a portrait of the groups is made by studying the distribution of each variable in each one of them in order to extract selection criteria to be applied later.

\section{Results}

Table 1 gives the results of geometric measurements and compressive strength $\left(\sigma_{\max }\right)$ obtained on the 44 samples.

The principal component analysis was carried out using the 8 basic variables $\left(a, b, d, E, F, S_{\text {tot }}, S_{\text {cort }}\right.$, poros$i t y$ ). The graph (Fig. 6) of the projections of the variables on the two first axes shows that the thickness parameters $(a, b, d)$ have a strong correlation between each other and with the cortical surface area $S_{\text {cort }}$ around axis 1, and the width and length parameters $(E, F)$ with the total surface area $S_{\text {tot }}$ and towards axis 2. They thus appear to be essential for the rest of the study. 


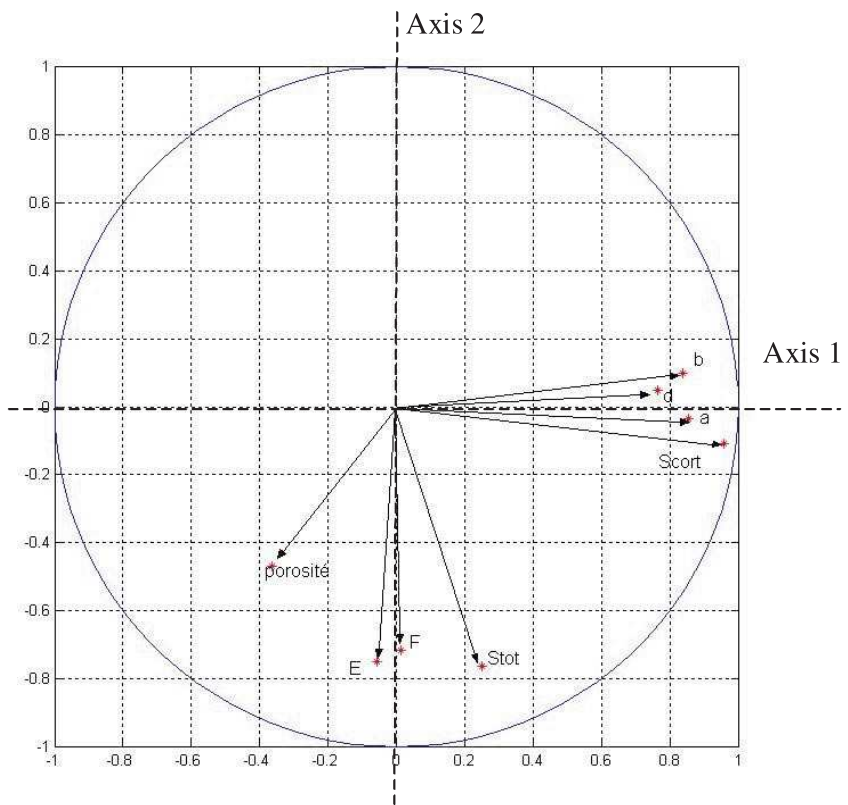

Fig. 6. Principal components analysis for 8 basic variables.

Table 1. Descriptive statistics, geometric measurements and compressive strength.

\begin{tabular}{lcccc}
\hline$n=44$ & Age & $\begin{array}{c}S_{\text {tot }} \\
\left(\mathrm{mm}^{2}\right)\end{array}$ & $\begin{array}{c}S_{\text {cort }} \\
\left(\mathrm{mm}^{2}\right)\end{array}$ & $\begin{array}{c}\sigma_{\max } \\
\mathrm{MPa}\end{array}$ \\
\hline Mean & 70 & 114 & 81 & 90 \\
Standard deviation & 12 & 25 & 19 & 32 \\
Minimum & 43 & 73 & 36 & 10 \\
Maximum & 94 & 195 & 136 & 158 \\
\hline
\end{tabular}

To the 7 basic dimensional characteristics $(a, b, d, E$, $\left.F, S_{\text {cort }}, S_{\text {tot }}\right)$ and porosity are added three new variables. They express the additional mechanical properties linked to the thinness of the sample $(a / F,(b+d) / 2 E)$, and to the mean cortical surface area $(E(a+b+d) / 3)$. We thus carried out a new PCA with these 11 variables.

Distribution similar to the first PCA is again observed: one group of 7 variables (framed in Fig. 7), very correlated between themselves and with the cortical surface area around axis 1 , and a second one linked to axis 2 , consisting of $E, F$ and the total surface area. It can be seen in the two graphs that the apparent porosity does not stand out as being a variable correlated with the other parameters but is rather in opposition on axis 1 to the 1st group of variables.

Since the objective was to produce a classification of the bone wedges from variables or combinations of simple geometric variables, several choices were possible. From the previous PCA, the three variables with the greatest mechanical significance were chosen (cortical surface area $S_{\text {cort }}$, and the thinness parameters $a / F$ and $\left.(b+d) / 2 E\right)$.

The hierarchical cluster analysis of the individuals was then carried out in the Euclidean space of the three variables chosen. Figure 8 shows the distribution and classification of the individuals (on the abscissas) relative to the Euclidean distance on the ordinates obtained by the

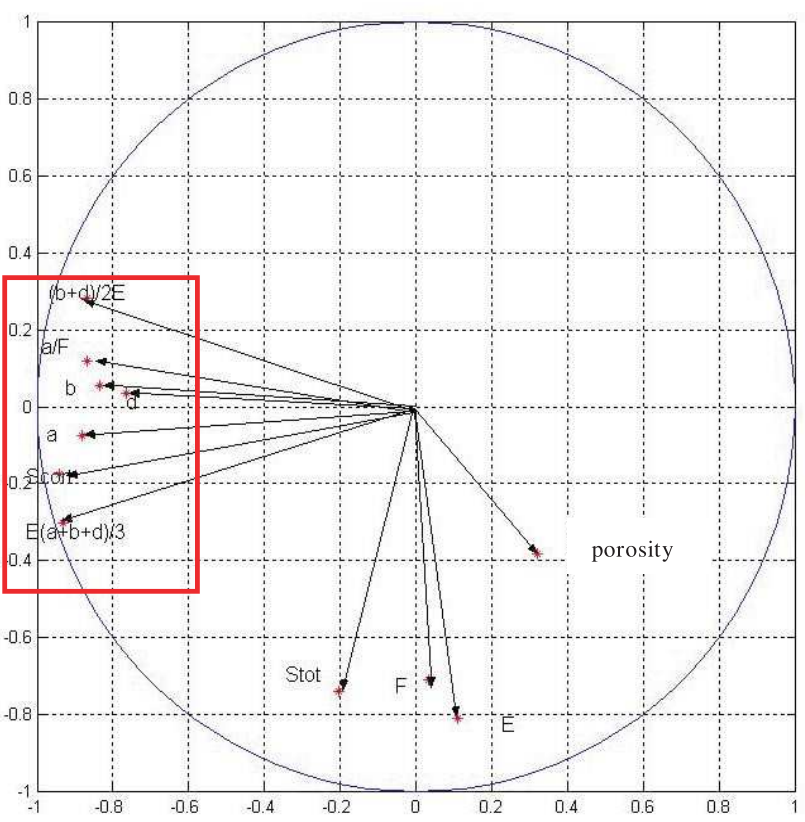

Fig. 7. Principal components analysis for 11 basic variables.

Table 2. Characteristic parameters of group $G 1(n=26)$.

\begin{tabular}{lcccc}
\hline$n=26$ & $\begin{array}{c}S_{\text {cort }} \\
\left(\mathrm{mm}^{2}\right)\end{array}$ & $\begin{array}{c}a / F \\
(-)\end{array}$ & $\begin{array}{c}b+d / 2 E \\
(-)\end{array}$ & $\begin{array}{c}\sigma_{\max } \\
(\mathrm{MPa})\end{array}$ \\
\hline Mean & 85.1 & 0.36 & 0.103 & 103 \\
Standard deviation & 9.3 & 0.05 & 0.016 & 28.3 \\
Minimum & 69 & 0.27 & 0.0774 & 43 \\
Maximum & 103.8 & 0.48 & 0.132 & 158 \\
\hline
\end{tabular}

"Average between groups" method and starting from the three chosen variables $S_{\text {cort }}, a / F$ and $(b+d) / 2 E$ centred and reduced. The cut off at the distance $d=1.8$ produces 4 distinct groups and one isolated sample.

Calculation of classic statistics for the 4 groups $(G 1$, $G 2, G 3, G 4)$, shows that group No. 1 has a mean maximal stress $\left(\sigma_{\max }=103 \mathrm{MPa}, n=26\right)$. This group included 26 samples but one of them had a very low stress (No. 32, $\left.\sigma_{\max }=43 \mathrm{MPa}\right)$. Examination of it showed the presence of osteophytes in the cortex. We chose to eliminate it: this did not influence the grouping. On the other hand, in terms of compressive strength, the group then had a higher minimal stress. Table 2 gives the descriptive statistics of the representative group $G 1$. Group $G 2$ shows an intermediate mean stress $\left(\sigma_{\max }=75 \mathrm{MPa}, n=11\right)$, group $G 3$ a very low mean stress $\left(\sigma_{\max }=37 \mathrm{MPa}, n=3\right)$ while group $G 4$ has three samples with geometric parameters clearly greater than all the others $\left(\sigma_{\max }=89 \mathrm{MPa}\right.$, $n=3$ ).

This sorting allows the most resistant samples to be selected. We therefore propose the following criteria, based on the minimums obtained in group 1:

$-S_{\text {cort }}>69 \mathrm{~mm}^{2}$.

$-a / F>0.27$.

$-(b+d) / 2 E>0.0774$. 


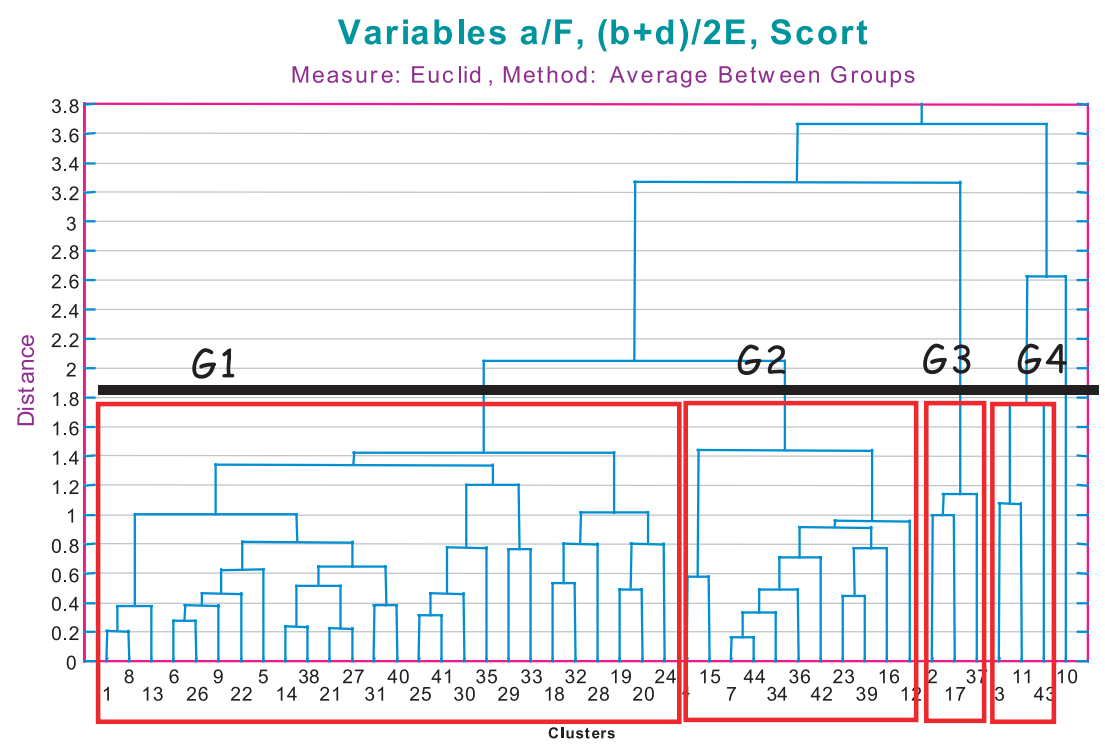

Fig. 8. Grouping of samples $(n=44)$.

Table 3. Characteristic parameters of group $G 1(n=25)$ having eliminated the sample with osteophytes.

\begin{tabular}{lcccc}
\hline$n=25$ & $\begin{array}{c}S_{\text {cort }} \\
\left(\mathrm{mm}^{2}\right)\end{array}$ & $\begin{array}{c}a / F \\
(-)\end{array}$ & $\begin{array}{c}(b+d) / 2 E \\
(-)\end{array}$ & $\begin{array}{c}\sigma_{\max } \\
(\mathrm{MPa})\end{array}$ \\
\hline Mean & 84.7 & 0.36 & 0.102 & 105 \\
Standard deviation & 9.2 & 0.05 & 0.015 & 26.1 \\
Minimum & 69 & 0.27 & 0.0774 & 61 \\
Maximum & 103.8 & 0.48 & 0.132 & 158 \\
\hline
\end{tabular}

Nevertheless, it is relatively difficult experimentally to determine the value for the cortical surface area $S_{\text {cort }}$. As it has been shown that this surface area was correlated to the geometric parameters (Fig. 6), a regression law was sought which would allow calculation of this value from simple measurements.

A stepwise regression analysis led to the selection of the variables $\left(E(a+b+d) / 3, E, E^{2}\right)$ on the basis of the optimum $r^{2}$ of 0.995 to express the cortical surface area $\left(S_{\text {cort }}\right)$, the factor $E(a+b+d) / 3$ representing the mean cortical surface area, the parameter $E$ being linked to the mean circumference of the sample and $E^{2}$ to the total surface area of the sample.

The equation obtained is as follows, calculated for 44 samples (standard error $\left.=6.16 \mathrm{~mm}^{2}\right)$ :

$$
\begin{aligned}
& S_{\text {cortcalculated }}= \\
& \qquad 2.4715 E+1.1799 \frac{a+b+d}{3} E-0.0816 E^{2} .
\end{aligned}
$$

It is thus possible to estimate numerically the cortical surface area $S_{\text {cort }}$ previously measured by scanning and digitalisation of each surface of the sample.

Thus, the cortical surface area $S_{\text {cort }}$ will be replaced by the calculated cortical surface area $S_{\text {cort calculated }}$ in the preceding selection criteria.
If these selection criteria are applied to the 44 preceding samples, a representative group of 29 individuals is obtained. Its characteristics are as follows (Tab. 4).

\section{Discussion}

It should be remembered that the series of samples $(n=$ 44) used in this study had been previously tested without taking particular precautions in their selection (age, sex). Only the angle of the wedge $(\beta)$, associated with the height $(h)$, and the sex of the donors was considered in the first study. It has been shown [8] from 4 batches of 11 samples, that the three parameters chosen $(\beta$, age, sex) have no significant influence on compressive strength. But the wide range obtained for this $[10-158 \mathrm{MPa}]$ required the development of a sample selection method reliably guaranteeing an acceptable minimal value and a greatly reduced range equivalent to those obtained with similar materials suitable for osteotomies [25-100 MPa] [12]. It was to meet these two requirements that we re-examined our results using the statistical methods explained and discussed below.

Generally as is now fairly well known, the preparation of samples is very severe, quite noticeably decreasing the mechanical properties of the head of the femur depending on the type of cleaning process used: e.g. rotary or ultrasonic agitation [13] and the physico-chemical treatments used result in reduction of the mechanical properties of trabecular bone [14].

For the mechanical tests, the ready to use wedges were sectioned arbitrarily at $L=10 \mathrm{~mm}$ in the direction of the length of the neck. This value was chosen after 4 pre-tests on whole wedges, with the aim of conserving one of the dimensions homogeneous to all the samples. In addition, during implantation, the surgeon may decide to cut the bone wedge to facilitate its insertion. The surgical conditions for insertion are thus noticeably reproduced. 
Table 4. Parameters obtained for 29 samples selected from 44 individuals using the criteria given by the representative group $G 1$.

\begin{tabular}{lccccc}
\hline$n=29$ & $\begin{array}{c}S_{\text {cort }} \\
\left(\mathrm{mm}^{2}\right)\end{array}$ & $\begin{array}{c}a / F \\
(-)\end{array}$ & $\begin{array}{c}(b+d) / 2 E \\
(-)\end{array}$ & $\begin{array}{c}E(a+b+d) / 3 \\
\left(\mathrm{~mm}^{2}\right)\end{array}$ & $\begin{array}{c}\sigma_{\max } \\
(\mathrm{MPa})\end{array}$ \\
\hline Mean & 89 & 0.38 & 0.108 & 62.92 & 103 \\
Standard deviation & 15 & 0.07 & 0.023 & 13.8 & 26 \\
Minimum & 69 & 0.27 & 0.0774 & 44.87 & 61 \\
Maximum & 136 & 0.57 & 0.184 & 101.55 & 158 \\
\hline
\end{tabular}

To determine the measurements of the different surface areas $\left(S_{\text {cort }}\right.$ and $\left.S_{s p}\right)$, we scanned the faces of each sample. Measurement bias was thus possible when the cortical part had to be delineated from the spongy part. In addition, the surface area and the geometric values obtained came from the mean of the values for the two faces, this operation necessarily affecting the precision of the calculations.

The porosity that we calculated is a mean apparent surface porosity and not a volumetric porosity. It must therefore be considered as a simple indicator, which has been proved moreover not to be significant in terms of influence on the mechanical strength of the samples.

The choice of using thinness variables was made to express a certain fragility of the samples. But a slenderness parameter, which is classically used in compression:

$$
\text { slenderness } \gamma=h / \rho
$$

with

$$
\text { Inertia }_{\text {cortical }}=S_{W} \rho^{2}
$$

could have been envisaged. Only the fairly delicate, in practice, calculation of inertia led us to choose the simpler method, calling upon a single notion of thinness.

Tests undertaken on bone wedges of human origin naturally lead to compression and shear stresses within the samples. During the calculation of maximum strength under compression $\sigma_{\max }$, we only considered compression stress, because this is dominant. In fact, for the maximum angle $\beta$ of $12^{\circ}$, the maximum shearing force, connected to the fact that the bearing faces are not parallel, may reach $21 \%\left(\sin 12^{\circ}\right)$ of the overall stress measured. But it has been shown in the literature $[15,16]$ that the ultimate shearing stress $\left(\tau_{\text {ultimate }}\right)$ reaches approximately $50 \%$ of the ultimate stress under compression $\sigma_{\text {ultimate }}$ (i.e. $\tau_{\text {ultimate }}=60-80 \mathrm{MPa}$ and $\sigma_{\text {ultimate }}=$ 170-190 $\mathrm{MPa}$ on moist compact bone from the human femur).

It should also be noted that the effect of friction existing at the bone/metal interface was taken into account, the coefficient of friction being in the region of $\alpha=0.16$ [17]. This is also a physical reality on implantation of osteotomy wedges (interface bone/moist bone). If the influence of friction and shearing due to the inclination of the bearing surfaces is taken into account, the following is obtained:

$$
\tau_{\beta} \approx 21 \% \sigma_{\text {ultimate }}
$$

and

$$
\tau_{\alpha} \approx 16 \% \sigma_{\text {ultimate }}
$$

That is a maximum of $37 \% \sigma_{\text {ultimate, a value which re- }}$ mains lower than that given in the literature (50\%) and which shows the predominance of compression stress in our test, reproducing in fact rather well the physiological situation of osteotomy wedges. The limit stresses are thus determined by default, taking into account the penalising effect of shearing stresses, making these results reliable.

The absence of alignment between the mechanical load and the mean direction of the cortex can also bring about measurement bias but numerous other independent factors which are difficult to measure are also involved in the overall strength of osteotomy wedges (overall geometry, age, pathology, site in the neck from which the wedge is taken, etc.). It should also be remembered that interindividual variations in mechanical properties of cortical bone under compression, cited in the literature $[15,18]$ (from 127 to $296 \mathrm{MPa}, 7$ subjects between 17 and 83 years old, i.e. from a given value to more than double that figure), are similar to those recorded during our tests.

In the first instance, the application of PCA has allowed fairly easy visualisation of two groups of dimensional variables which are clearly uncorrelated one with the other, one group naturally associating the cortical surface area with thicknesses $a, b, d$ and the other group associating the total surface area equally naturally with the width and length of the bone wedge. Secondly, in order to introduce physical parameters (thinness) which generally play a role in mechanical strength and in the end perhaps to get closer to the calculation of $S_{\text {cort }}$, three new variables have been added to the analysis. It can be seen that these are integrated into the 1st group and justify a priori their choice in the rest of the study.

During the statistical study, several choices of current methods of hierarchical classification were possible (Average Between Groups, Average Within Groups, Single Linkage, Centroid, Median, etc.) but these all led more or less to the same sample groupings.

If the variables which permitted the classification are then considered (i.e. $S_{\text {cort }}$, and the thinness parameters $a / F$ and $(b+d) / 2 E)$, it becomes evident that group 1 (the representative group) is characterised by parameter values which deviate positively from the mean, whilst group 2 deviate negatively, group 3 very negatively and the other samples very positively.

Following this sorting, a selection of the most resistant samples was possible from the scanner measurements (resolution 600 dpi i.e. $\sim 40 \mu \mathrm{m}$ ) of basic geometric parameters $(a, b, d, E, F)$ allowing indirect calculation of the cortical surface area. In practice, the dimensions could be measured on the samples taken using a micrometer 
(accuracy $0.05 \mathrm{~mm}$ ). Particular care should however be taken over these measurements in order to ensure consistency of the method. Thus, direct geometrical measurements only (such as cortical thickness at different points $(a, b, d)$, and the width $E$ of the sample) allow the cortical surface area of the bone wedge taken from femoral head neck to be predicted. Various regressions taking into account several combinations of variables have been studied. These gave very satisfactory correlation coefficients $\left(r^{2}>0.8\right)$ but we have kept the variables which have a physical representation and an optimum $r^{2}$ (0.995). In general, the coefficient $E(a+b+d) / 3$ appears to be necessary in all these regressions, a fairly obvious observation considering that it represents a good approximation to the cortical surface area. It should nevertheless be noted that we deliberately eliminated one sample, due to the presence of osteophytes on the cortex. In fact, the presence of this abnormality led to over estimation of various geometrical parameters above all of surface areas, which did not place the sample in the right group. Particular care should thus be given to preliminary choice of bone wedges rejecting those having cortical osteophytes.

\section{Conclusions}

The simple geometric parameters that we chose in order to select bone wedges are relatively easy to measure ( $a$, $b, d, E, F)$ and the chosen criteria ensure a satisfactory range of compressive strength. Statistically, $95 \%$ of the samples have a maximum stress between 50 and $154 \mathrm{MPa}$ (mean \pm 2 standard deviation). By selecting the samples according to the proposed method, the mean mechanical strength $(105 \mathrm{MPa})$, the range of strength provided by the sorted group $[61-158 \mathrm{MPa}]$ and the minimum value $(61 \mathrm{MPa})$ are in the superior range of materials suitable for osteotomies.

The authors would like to thank the Tissue Bank of France (TBF) for the furnishing of the openwedges and for their technical assistance.

\section{References}

1. P. Hernigou, H. Ovadia, D. Goutallier, Rev. Chir. Orthop. 78, 258 (1992)

2. J.L. Thomine, A. Boudjemaa, Y. Gibon, N. Biga, Rev. Chir. Orthop. 67, 319 (1981)

3. G. Poumarat, M. Dabonneville, Orthop. Traumatol. 2, 265 (1992)

4. G. Poumarat, P. Squire, Biomatérial 14, 337 (1993)

5. M. Trecant, J. Delecrin, J. Royer, E. Goyenvalle, G. Daculsi, Clin. Mater. 15, 233 (1994)

6. G. Guillemin, J.L. Patat, J. Biomed. Mater. Res. 21, 557 (1987)

7. J.C. Le Huec, T. Schaeverbeke, D. Clement, J. Faber, A. Le Rebeller, Biomaterials 16, 113 (1995)

8. H. Follet, R. Bardonnet, C. Rumelhart, Arch. Physiol. Biochem. 109, 95 (2001)

9. K. Thoren, P. Aspenberg, K.-G. Thorngren, Clin. Orthop. 311, 232 (1995)

10. M. Vollé, Analyse des données, edited by Economica (Paris, 1997), 320 p., ISBN 2-7178-3212-2

11. G. Saporta, Probabilité, analyse de donnée et statistique, edited by TECHNIP (Paris, 1990), 400 p., ISBN 2-7108-0565-0

12. Association pour l'étude des Greffes Et Substituts Tissulaires de l'Appareil Locomoteur. http://www.maitrise-orthop.com/gesto

13. K. Bruyère, R. Bardonnet, D. Mitton, C. Rumelhart, in Bone allograft preparation using ultrasonic stirring: mechanical validation, 8th World Congress of SIROT, Sydney, Australia, April 1999

14. O. Cornu, X. Banse, P.L. Docquier, S. Luyckxs, C. Delloyec, J. Orthop. Res. 18, 426 (2000)

15. Y. Hiroshi, Strength of biological materials, edited by F. Gaynor Evans (Robert E. Krieger publishing company, Huntington, New York, 1973), pp. 38-43

16. S.C. Cowin, Bone Biomechanics Handbooks, 2nd edn. (CRC Press, New York, 2001), ISBN: 0-8493-9117-2

17. D. Dowson, V. Wright, Introduction to the biomechanics of joints and joint replacement (Mechanical engineering publications Ltd, London, 1981), p. 54, ISBN 0-8529-8384-0

18. J.J. Comtet, R. Rozier, R. Vassal, J.M. Arene, L. Fischer, Rev. Chir. Orthop. 53, 3 (1967)

To access this journal online: www.edpsciences.org 